\title{
Scaphocephaly, bilateral aniridia, and bilateral anterior polar cataract with posterior dislocation of the lens
}

\author{
H. MOHAN, D. K. SEN, AND D. K. GUPTA \\ Department of Ophthalmology, Irwin Hospital, New Delhi, India
}

Graniofacial dysostoses are rare conditions in which the growth of the skull is interfered with at right-angles to the obliterated suture and the expanding brain is forced to grow: in another direction. These dysostoses have been classified in various ways and the following types have been taken by Duke-Elder (1964) as typical: oxycephaly (tower ${ }_{0}^{N}$ skull); scaphocephaly (scaphoid head); plagiocephaly (slanting head); trigonocephaly, $\stackrel{\longrightarrow}{\longrightarrow}$ platycephaly, and hypertelorism. The underlying anomaly seems to be a failure in thes development of the primitive mesoderm from which the bones of the skull develop.

The purpose of this paper is to report the occurrence of aniridia with other anomalies in $\stackrel{\mathbb{D}}{3}$ a patient with a craniofacial dysostosis. This association has not previously been@ reported.

\section{Case report}

An 8-month-old baby was brought to the Eye Department of the Irwin Hospital because of an abnormally shaped skull, "shaking" of the eyes, and delayed physical progress. The mother'so pregnancy and delivery had been normal and there was no family history of similar defects.

EXAMINATION

The skull was very long in proportion to its width (Figs 1 and 2). There was no frontal bossing and? the sagittal suture was prominent to palpation.

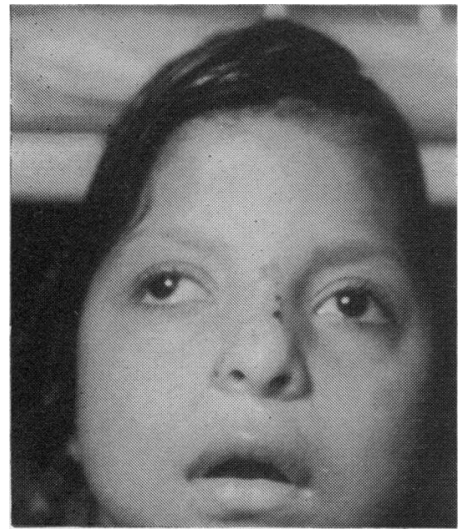

FIG. I Narrow skull and right concomitant divergent squint

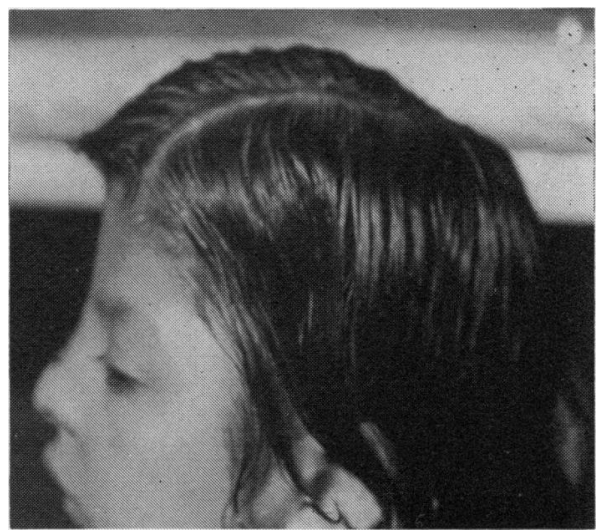

FIG. 2 Length of skull. Note that there is no frontal bossing 
Both eyes showed a horizontal, pendular, congenital nystagmus, associated with a right concomitant divergent squint of about $20^{\circ}$. The irides were completely absent in both eyes, but gonioscopy revealed a rudimentary iris stump hidden behind the corneo-scleral margin.

A small (diameter $1.5 \mathrm{~mm}$.), flat, circumscribed anterior polar cataract was also present in both eyes. Ophthalmoscopy showed bilateral post-papillar optic atrophy.

Systemic examination revealed no other abnormality, but radiographs showed a typical silverbeaten appearance of the skull with enlargement of the sella and destruction of the posterior clinoid processes. The orbits were shallow.

PROGRESS

The child was brought to us again nearly 2 years later, when the lenses in both eyes were found to be dislocated into the vitreous. There was no history of trauma to account for the dislocation and the eyes were white and quiet. There was no evidence of uveitis or secondary glaucoma.

\section{Summary}

An unusual association is reported of aniridia and anterior polar cataract in a case of scaphocephaly. Both lenses subsequently dislocated spontaneously into the vitreous.

\section{References}

Duke-elder, s. (1964) “System of Ophthalmology", vol. 3, Pt. 2, pp. 566, 1037. Kimpton, London 